\title{
TECHNO-ECONOMIC ASSESSMENT FOR INSTALLATION OF INVELOX WIND TURBINES IN NORTHERN IRAN
}

UDC: 521.548

Original scientific paper

https://doi.org/10.18485/aeletters.2021.6.4.1

\author{
Pooya Taheri ${ }^{1^{*}}$, Mohammad Javad Taheri $^{2}$ \\ ${ }^{1}$ Mechatronic Systems Engineering Department, Simon Fraser University, Canada \\ ${ }^{2}$ Niroo Consulting Engineers, Tehran, Iran
}

\begin{abstract}
:
This paper aims to provide a comprehensive feasibility study for the installation of a $100 \mathrm{MW}$ wind power plant using the INVELOX system in Manjil, Gilan, in Northern Iran. In the first part of the paper, we provide a review of the status of wind energy installation in Iran. We then review the mathematical equations involved in wind power calculations. Afterwards, with the environmental data gathered from the corresponding authorities and open-access sources, we analyzed the INVELOX system with its benefits and drawbacks. Then, based on the derived mathematical formulations, and using simulation software packages, the average wind power density is calculated, and the turbine system is designed accordingly. Finally, the economic profitability of this project was examined using a mathematical economic analysis and the COMFAR software package. In addition to the detailed feasibility study of this specific project, this article aims to provide a comprehensive literature review of the INVELOX system.
\end{abstract}

ARTICLE HISTORY

Received: 28.08.2021.

Accepted: 08.10.2021.

Available: 31.12.2021.

\section{KEYWORDS}

Economic analysis, Feasibility study, Fluid dynamic, INVELOX wind turbine, Wind energy.

\section{INTRODUCTION}

The production of alternative energy is a critical issue. The search for innovative ways to harness wind, water, and solar power has led engineers and scientists to develop novel designs that can increase efficiency and boost energy output. Fossil fuels have been used throughout the world since the 1700s. In the eighteenth century, the industrial revolution facilitated the use of substances derived from fossil fuels, including coal, gasoline, diesel, and petrol. These sources of energy are available in nature for utilization, but they are not sustainable [1]. These sources of energy also have associated disadvantages, such as high costs and increased emissions that pollute and damage the ecosystem. From the seventies, the world began experiencing an energy crisis because of the inherent flaws in reliance on fossil fuels. As such, there was a need to find and embrace new approaches to generating energy.
Based on this necessity, process-based energy forms were created. This involved the use of nonconventional sources of energy like hydro, geothermal, tidal, wind, and solar. From all this, wind is the most harnessed energy source [2]. Historically, wind energy has been used for irrigation, windmill operation, air conditioning, and ventilation. Historical evidence shows that the utilization of wind energy in the Persian Empire (current Iran) goes back to $200 \mathrm{BC}$. Windcatchers or windbreakers as an architectural design for buildings in the city of Yazd located on the desert boundary in Iran has been popular for ventilation and air conditioning for years. This traditional concept has inspired many innovative designs in recent years. Fig. 1 shows different traditional windcatchers in desert cities of Iran, countries in the Persian Gulf region, and other Middle Eastern countries [3-5]. In these buildings, an air trap conducts the air from different directions through a duct into the building. The pressurized air is then ventilated through the seams and cracks of 
windows and doors, leading to natural air circulation and conditioning.

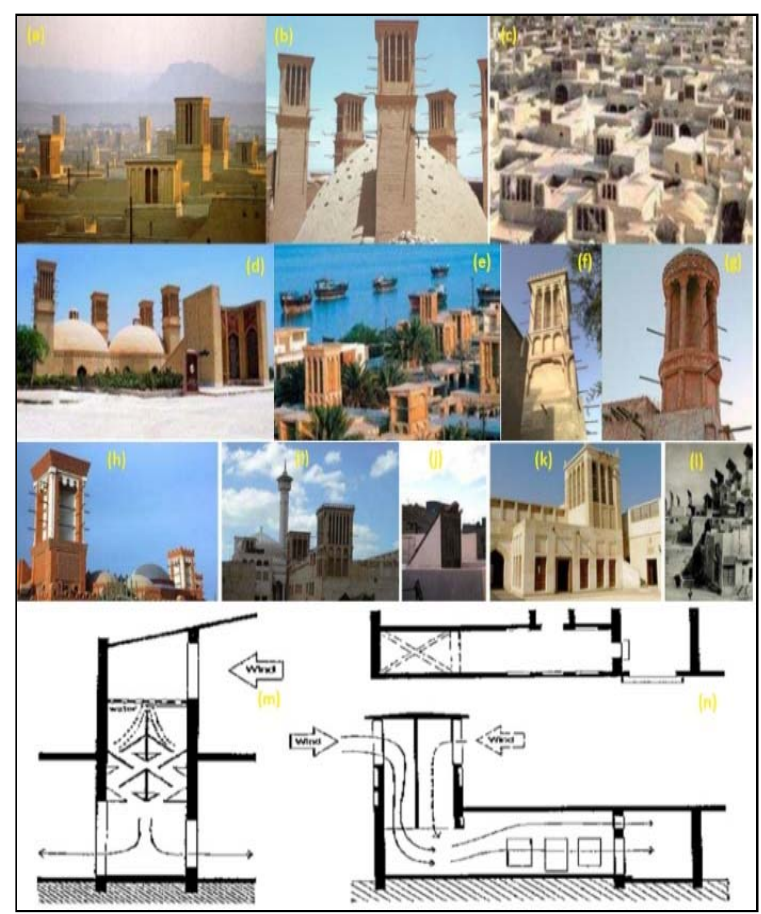

Fig. 1. Traditional windcatcher samples [3-5]: (a) windcatchers in Yazd, Iran; (b) four-sided windcatcher in Yazd, Iran; (c) one-sided windcatchers (badgir) in Meybod, Iran; (d) four-sided windcatcher in Kish Island, Iran; (e) windcatchers in hot and humid southern climate of Iran; (f) windcatcher in Bastakiya Quarter, Dubai; (g) cylindrical windcatcher in Dubai; (h) decorative barjeel in Qatar; (i) wind tower (barjeel) in the Bastakiya Quarter, Dubai; (j) windcatcher (malqaf) in Bayt Al-Suhaymi, Egypt; (k) barjeel in Bahrain; (I) mungh in Pakistan; (m) evaporative cooler mechanism; ( $n$ ) multidirectional windcatcher mechanism

According to the Paris Agreement on climate change, Iran was mandated to decrease its Greenhouse Gas (GHG) emissions up to $12 \%$ by 2030. Since 2014, Iran's Ministry of Energy has supported the development of renewable energy power plants. The generated power from renewable energy plants is purchased for 20 years under the Power Purchase Agreement (PPA) by the Renewable Energy and Energy Efficiency Organization (SATBA) [6]. The new range of tariffs, depending on the type of renewable energy technology and the power plant capacity, varies from 9.7 US cents to 22.8 US cents per kWh. Fig. 2 shows the yearly changes in the investment cost of renewable power plants, the yearly changes of electricity costs by renewable energy technology, and the capacity growth of installed wind plants globally and in Iran.

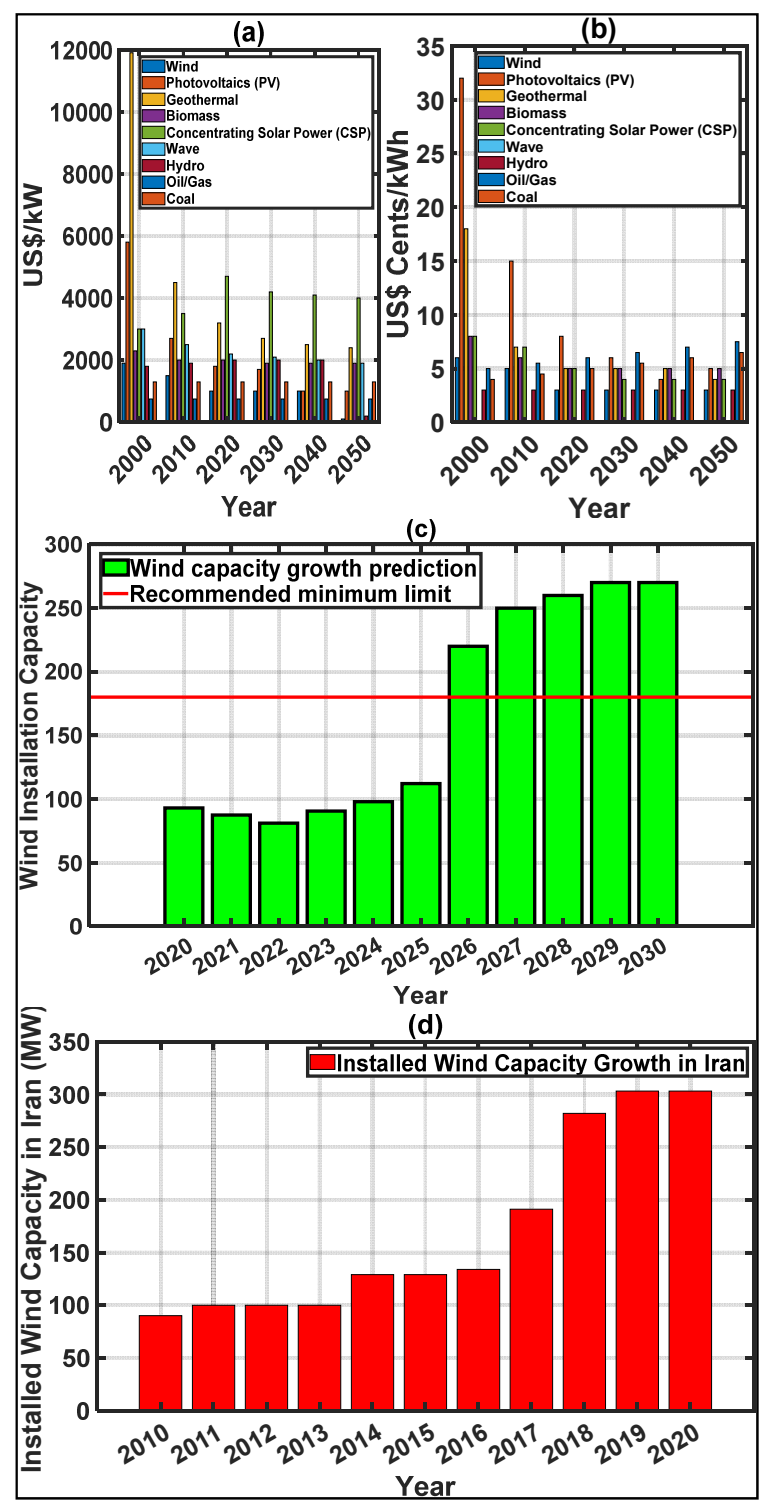

Fig. 2. (a) 2000-2050 yearly change of investment cost of renewable power plants; (b) 2000-2050 yearly changes of electricity cost by renewable energy technology [7,8]; (c) 2020-2030 predictions for required wind power capacity to slow down the global warming [9]; and (d) 2010-2020 wind power capacity growth in Iran [10]

The first modern wind turbines, two sets of $500 \mathrm{~kW}$ Nordtank, were installed in Manjil and Roodbar (two cities in Northern Iran) in 1994 and 2013. In 2019, the total capacity of wind power stations in Iran was $282 \mathrm{MW}$. In 2020, this capacity increased to $302.82 \mathrm{MW}$, while the total capacity of the national grid in Iran was 81,295 MW [11]. Currently, renewable energy makes up less than $5 \%$ of electrical power generation in Iran, but it has the potential to increase up to $38 \%$ by 2030 . Estimates of wind power potentials in Iran range widely between $6,500 \mathrm{MW}$ to $16,000 \mathrm{MW}$. International 
studies have shown that wind power has the potential to generate $22 \mathrm{TWh} /$ year of electricity in Iran by 2030. In the Iranian Ministry of Energy's plan, wind power capacity is expected to increase from $200 \mathrm{MW}$ in 2017 to $1,187 \mathrm{MW}$ in 2030 [12]. Developing renewable energy sources is regarded as a suitable option to conquer the destructive effects of fossil fuels on the environment. Renewable energies are clean, environmentally preferable, ubiquitous, and inexhaustible.

Presently, wind turbines exist in almost all parts of the world. To satisfy the increasing energy demands, bigger generators and turbines with larger blades are required to be installed on taller towers. Resulting in additional expenses that may exceed the cost of generating energy from hydro or numerous other sources [13]. Furthermore, wind turbines also negatively impact wildlife and human populations because of their tendency to produce sound waves at low frequencies. To keep global warming below $2{ }^{\circ} \mathrm{C}$, wind installations must ramp up globally in this decade [9]. Numerous innovators all over the globe have begun seeking solutions to address these challenges. The amount of energy harvested by a wind turbine depends on the wind direction and speed; therefore, to maximize the energy output of the wind turbine, the turbine's blade and yaw shall be controlled based on the wind strength and direction.

According to a previous study [14], Manjil is considered a very favorable region for wind farm construction due to its environmental factors. In this feasibility study, we investigated a newer model of the wind turbine, called INVELOX (Increased Velocity), whose performance does not depend on the wind direction [15]. The design of this model is inspired by the traditional windcatchers used for ventilation in the hot cities of Yazd province in Iran. INVELOX is a patented technology created for capturing and delivering wind energy, which allows for more engineering control. While conventional wind turbines utilize turbine generators attached to the top of the towers, the INVELOX system funnels energy from the wind on the ground. It is a system, shaped in the form of a funnel, that captures the omnidirectional air and quickly pushes it to drive the generator installed in the venturi section of the system. As such, INVELOX provides an economical, clean, and safe energy output.

In Section 2 of this paper, we provide the mathematical formulation for calculating the potential wind power and energy for any geographical location. In Section 3, the geographical and environmental data are presented and analyzed to calculate the expected wind power density. Section 4 introduces the INVELOX wind system and the corresponding practical considerations. The economic feasibility of the project is evaluated in Section 5. Finally, Section 6 concludes the results of this paper.

\section{WIND POWER MATHEMATICAL CALCULATIONS}

In this section, we present different mathematical calculations to estimate the potential wind power capacity in any given geographical location. The Power Capacity $\left(\boldsymbol{C}_{\boldsymbol{P}}\right)$ is defined as the energy received from the turbine divided by the wind energy before hitting the turbine.

\subsection{Maximum Efficiency of a Wind Turbine}

The energy of a constant-speed wind before hitting the turbine impeller may be calculated by the following equation:

$$
P=\frac{d E}{d t}=\frac{d}{d t}\left(\frac{1}{2} m v^{2}\right)=\frac{1}{2} \rho A v^{3}=\frac{1}{8} \rho \pi d^{2} v^{3}
$$

where $\boldsymbol{m}$ is the mass of air passing through the impeller, $\boldsymbol{v}$ is the wind speed, and $\boldsymbol{A}$ is the surface area impacted by the wind.

For two turbine impellers with different diameters $\boldsymbol{d}_{\mathbf{1}}$ and $\boldsymbol{d}_{\mathbf{2}}$, in the same weather conditions (stable density) and stable wind speed, the ratio of generated powers $\left(\boldsymbol{P}_{\mathbf{1}} / \boldsymbol{P}_{\mathbf{2}}\right)$ is calculated as follows:

$$
\frac{P_{1}}{P_{2}}=\left(\frac{d_{1}}{d_{2}}\right)^{2}
$$

This means that to increase the generation capacity of traditional wind turbines, the diameter should increase. The power absorbed by the impeller from the wind energy, shown in Fig.3, is equal to $P$ in the following equations:

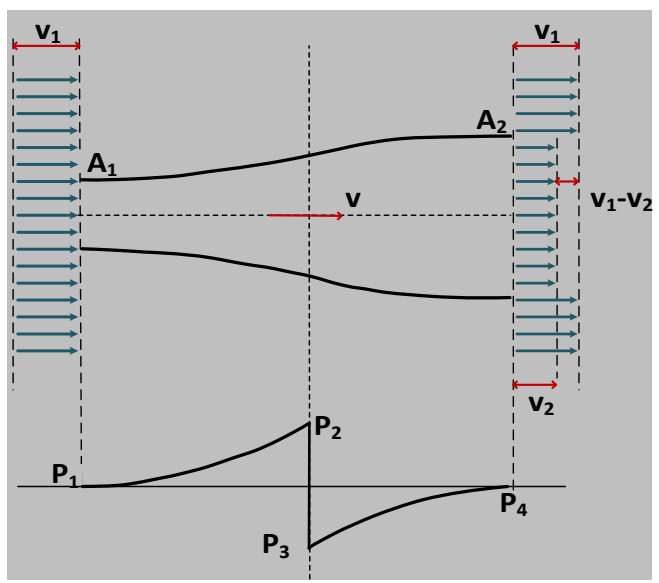

Fig. 3. Wind flow through an impeller 


$$
\begin{aligned}
& P=\frac{1}{2} \rho A\left(v_{1}^{2}-v_{2}^{2}\right) \\
& P=\rho A v\left(v_{1}-v_{2}\right)
\end{aligned}
$$

where $v_{1}$ is the speed in front of the rotor, $v_{2}$ is the speed downstream of the rotor, $v$ is the speed at the fluid power device, $\boldsymbol{\rho}$ is the fluid density, and the area of the turbine is given by $\boldsymbol{A}$. Both expressions for power are completely valid, one was derived by examining the incremental work done, and the other by the conservation of energy. Equating these two expressions yields an interesting result:

$$
v=\frac{1}{2}\left(v_{1}+v_{2}\right)
$$

Therefore, the wind velocity at the rotor may be taken as the average of the upstream and downstream velocities. The power equation can be derived by differentiating the kinetic energy expression with respect to time $(\boldsymbol{t})$ :

$$
\dot{E}=\frac{1}{2} \dot{m}\left(v_{1}^{2}-v_{2}^{2}\right)=\frac{\rho A v_{1}^{3}\left(1-a^{2}+a-a^{3}\right)}{4}
$$

where $a=v_{2} / v_{1}$, and $E$ is the kinetic energy. By differentiating the power expression with respect to $\boldsymbol{a}$ for a given fluid speed and a given area, one finds the maximum power:

$$
\dot{E}=0 \Rightarrow a=\frac{1}{3} \Rightarrow P_{\text {max }}=\frac{16}{27}\left(\frac{1}{2} \rho A v_{1}^{3}\right)
$$

The reference power for the Betz efficiency calculation is the power in a moving fluid in a cylinder with cross-sectional area $A$ and velocity $v_{1}$ :

$$
P_{\text {wind }}=C_{P} \cdot \frac{1}{2} \rho A v_{1}^{3}
$$

The power coefficient, $\boldsymbol{C}_{\boldsymbol{P}}=\boldsymbol{P} / \boldsymbol{P}_{\text {wind }}$, is a dimensionless ratio of the extractable power $P$ to the kinetic power $\boldsymbol{P}_{\text {wind }}$ available in the undistributed stream with a maximum value $C_{P_{\text {max }}}=16 / 27=0.593=59.3 \%[16]$. Therefore, the maximum ideal efficiency of an open-impeller wind turbine is equal to 0.59 . Today, the efficiency of open-impeller wind turbines ranges from $30 \%$ to $45 \%$. One of the factors that prevent the wind turbine efficiency to reach its ideal Betz state is the mechanical and friction head effect on the blades. Thus, the real power of the wind turbine is calculated from:

$$
\boldsymbol{P}=\boldsymbol{\eta} * \boldsymbol{C}_{\boldsymbol{p}} * \boldsymbol{\rho} / \mathbf{2} * \boldsymbol{A} * \boldsymbol{v}_{1}^{3}
$$

where $\boldsymbol{\eta}$ counts for the connection with the fluid and mechanical heads. If the impeller diameter increases beyond a limit, $\boldsymbol{\eta}$ and thus the output power of the turbine decreases. Therefore, in the study of turbine performance, the amount of energy exchanged depends not only on the wind speed but also on another factor called $\lambda$, Tip Speed Ratio (TSR), which is defined in Eq. 9:

$$
T S R=\frac{\text { Blade' }^{\prime} \text { Tip Speed }}{\text { Wind Speed }}=\frac{\omega D}{120 v}
$$

where $\boldsymbol{\omega}$ is the rotational speed (rpm), $\boldsymbol{D}$ is the blade's diameter $(\mathrm{m})$, and $\boldsymbol{v}$ is the wind speed $(\mathrm{m} / \mathrm{s})$.

\subsection{Wind Power Density (WPD) and Weibull Distribution}

To investigate the feasibility of wind energy resources at any site, the calculation of wind power is a crucial factor based on the measured values at the meteorological stations. The available wind power at elevation $\boldsymbol{h}$ above the ground flowing at speed $\boldsymbol{v}$ through blades with a sweeping area of $\boldsymbol{A}$ can be calculated by:

$$
P_{h}=\frac{1}{2} \rho A v_{h}^{3}
$$

where $\boldsymbol{\rho}$ is the air density $\left(\mathrm{kg} / \mathrm{m}^{3}\right)$. At sea level (1 atm pressure) and $15{ }^{\circ} \mathrm{C}$ temperature, $\boldsymbol{\rho}=$ $1.225 \frac{\mathrm{kg}}{\mathrm{m}^{3}}$. The monthly air density can be calculated using the following formula:

$$
\rho=\frac{\bar{p}}{R_{d} \bar{T}}
$$

where $\overline{\boldsymbol{T}}$ is the average monthly air temperature in ${ }^{\circ} \mathrm{K}, \overline{\boldsymbol{p}}$ is the average monthly air pressure, and $\boldsymbol{R}_{\boldsymbol{d}}$ is the gas constant which for dry air is $287 \mathrm{~J} /\left(\mathrm{kg} .{ }^{\circ} \mathrm{K}\right)$. In this formula, it is ideally assumed that the wind density is not dependent on the wind speed, which can introduce an error of up to 5\% [17]. The average WPD can be calculated as:

$$
\overline{W P D}=\frac{1}{2 n} \rho \sum_{i=1}^{n} v_{i}^{3}=\frac{1}{2} \rho \overline{v^{3}}
$$

where $\boldsymbol{n}$ is the number of data samples. If we denote $\boldsymbol{i}$ as the measured 3-hourly wind speed and $\boldsymbol{n}$ as the total wind-speed data samples for each year, the wind power density can be expressed as [18]:

$$
\frac{P}{A}=\int_{0}^{\infty} \frac{\rho v^{2}}{2} f(v) d v=\frac{\rho c^{3}}{2} \Gamma\left(1+\frac{3}{k}\right)
$$

where $\boldsymbol{f}(\boldsymbol{v})$ is the Weibull distribution function for wind speed obtained as:

$$
f(v)=\frac{d F(v)}{d v}=\left\{\begin{array}{cc}
\frac{k}{c}(v / c)^{k-1} e^{-(v / c)^{k}} & v \geq 0 \\
0 & v<0
\end{array}\right.
$$

$\boldsymbol{F}(\boldsymbol{v})$ is the Cumulative Distribution Function (CDF), $\boldsymbol{k}$ and $\boldsymbol{c}$ are the shape factor (dimensionless) 
and scale factor $(\mathrm{m} / \mathrm{s})$, respectively, and $\boldsymbol{\Gamma}$ is the gamma function defined as below:

$$
\Gamma(x)=\int_{0}^{\infty} e^{-u} u^{x-1} d x
$$

For the desired time duration ( $\boldsymbol{n} \boldsymbol{\Delta} \boldsymbol{t})$, wind energy density can be calculated as:

$$
\frac{E}{A}=\frac{P(n \Delta t)}{A}=\frac{\rho c^{3}}{2} \Gamma\left(1+\frac{3}{k}\right)(n \Delta t)
$$

When $\boldsymbol{k}=\mathbf{2}$, the Weibull distribution function is also referred to as the Rayleigh function. The main disadvantage of using the Weibull density function is the lack of accuracy in very low wind speeds. Several methods are found in the literature to estimate Weibull factors, four of which are briefed in Table 1. In this study, based on the acquired data, we selected the Power Density Method (PDM) which has an acceptable accuracy for the range of wind speed in Manjil $[19,20]$.

\begin{tabular}{|c|c|c|}
\hline Method & $\begin{array}{l}\text { shape factor }(k) \text { and } \\
\text { scale factor }(c)\end{array}$ & Eq. \# \\
\hline \multirow{2}{*}{ PDM } & $k=1+\frac{3.69}{E_{p f}^{2}}$ & (17 \\
\hline & $c=\frac{\bar{v}}{\Gamma(1+1 / k)}$. & (18 \\
\hline \multirow{2}{*}{$\begin{array}{l}\text { Standard } \\
\text { Deviation }\end{array}$} & $k=\left(\frac{\sigma}{\bar{v}}\right)^{-1.086}$ & (19 \\
\hline & $c=\frac{\bar{v}}{\Gamma(1+1 / k)}$ & (20 \\
\hline \multirow{2}{*}{$\begin{array}{l}\text { Maximum } \\
\text { Likelihood }\end{array}$} & $\begin{array}{c}k=\left[\frac{\sum_{i=1}^{n} v_{i}^{k_{\text {old }}} \ln \left(v_{i}\right)}{\sum_{i=1}^{n} v_{i}^{k_{\text {old }}}}-\right. \\
\left.\frac{\sum_{i=1}^{n} v_{i}^{k_{\text {old }}} \ln \left(v_{i}\right)}{n}\right]^{-1}\end{array}$ & (21) \\
\hline & $c=\sqrt[k]{\frac{1}{\mathrm{n}} \sum_{i=1}^{n} v_{i}^{k}}$ & (22 \\
\hline \multirow{2}{*}{$\begin{array}{c}\text { Modified } \\
\text { Maximum } \\
\text { Likelihood }\end{array}$} & $\begin{array}{c}k=\left[\frac{\sum_{i=1}^{n} v_{i}^{k}{ }_{\text {old }} \ln \left(v_{i}\right) f\left(v_{i}\right)}{\sum_{i=1}^{n} v_{i}^{k} \text { old } f\left(v_{i}\right)}-\right. \\
\left.\frac{\sum_{i=1}^{n} v_{i}^{k_{\text {old }}} \ln \left(v_{i}\right) f\left(v_{i}\right)}{f(v \geq 0)}\right]^{-1}\end{array}$ & (23 \\
\hline & $c=\sqrt[k]{\frac{1}{f(v \geq 0)} \sum_{i=1}^{n} v_{i}^{k} f\left(v_{i}\right)}$ & (24 \\
\hline
\end{tabular}

Table 1. Shape and scale factor approximation

In these equations, $\overline{\boldsymbol{v}}$ is the mean speed, $\boldsymbol{\sigma}$ is the standard deviation, and $\boldsymbol{\sigma}^{2}$ is the variance of wind speed calculated as:

$$
\begin{gathered}
\bar{v}=\frac{1}{n} \sum_{i=1}^{n} v_{i}=c \Gamma(1+1 / k) \\
\sigma^{2}=\frac{\sum_{i=1}^{n}\left(v_{i}-\bar{v}\right)^{2}}{n-1}=c^{2}\left[\Gamma\left(1+\frac{2}{k}\right)-\Gamma^{2}\left(1+\frac{2}{k}\right)\right]
\end{gathered}
$$

The energy pattern factor $\left(\boldsymbol{E}_{\boldsymbol{p} f}\right)$, which is the ratio of the average of cubic wind speed to the cube of average speed, is calculated as [18]:

$$
E_{p f}=\frac{\frac{1}{n} \sum_{i=1}^{n} v_{i}^{3}}{\left(\frac{1}{n} \sum_{i=1}^{n} v_{i}\right)^{3}}=\frac{\overline{v^{3}}}{\bar{v}^{3}}=\frac{\Gamma(1+3 / k)}{\Gamma^{3}(1+1 / k)}
$$

WPD takes the frequency distribution of the wind speed and the dependence of the wind power on air density into account, leading to a more accurate estimate. PDM is an easier approach to calculate the shape and scale factors with less computation. The total generated energy by the turbine in the time $\boldsymbol{T}$ can be calculated as:

$$
E_{\text {out }}=\boldsymbol{T} \int_{v_{i}}^{v_{o}} P(v) f_{\omega}(v) d v
$$

where $\boldsymbol{v}_{\boldsymbol{i}}$ and $\boldsymbol{v}_{\boldsymbol{o}}$ are the cut-in and cut-out speeds as shown in Fig. 4. The "cut-in speed" is the minimum speed at which the turbine can generate electrical energy. At speeds above the "cut-out speed", the turbine shuts down to avoid damage.

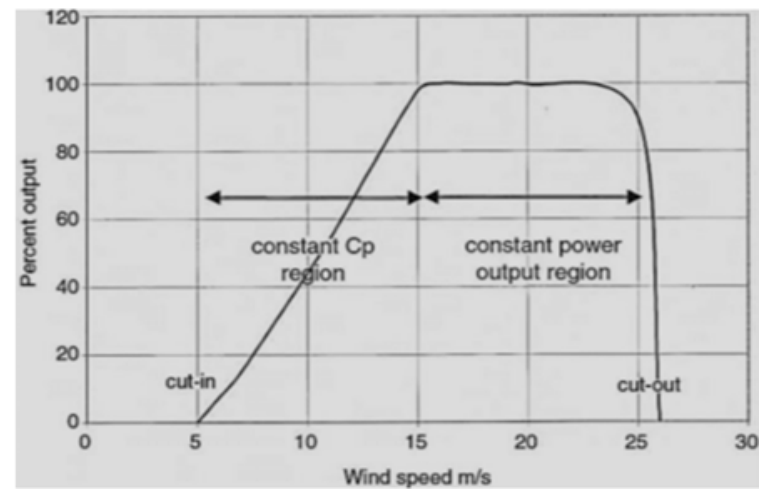

Fig. 4. Working regions of a wind turbine $[21,22]$

The Capacity Factor (CF) of a wind turbine, representing its efficiency, is defined as the ratio of the total generated energy over a period of time $\boldsymbol{T}$ to the energy that is generated at the rated power $[23,24]$ :

$$
C F=\frac{E_{\text {out }}}{E_{r}}=\frac{E_{\text {out }}}{P_{r} T}
$$

The most probable and optimal wind speeds $\left(\boldsymbol{v}_{\boldsymbol{m} \boldsymbol{p}}\right.$ and $\left.\boldsymbol{v}_{\boldsymbol{o p}}\right)$ are then calculated accordingly:

$$
\left\{\begin{array}{l}
v_{m p}=c \cdot \sqrt[k]{1-1 / k} \\
v_{o p}=c \cdot \sqrt[k]{1+2 / k}
\end{array}\right.
$$


where $\boldsymbol{v}_{\boldsymbol{o p}}$ is the wind speed generating the maximum energy, and the rated speed of the selected wind turbine should be close to $v_{o p}$ [17]. The wind power generation potential based on WPD has been categorized in [25] as shown in Table 2:

Table 2. Wind power potential at $\boldsymbol{h}=\mathbf{5 0} \mathbf{~ m ~ [ 2 5 ] ~}$

\begin{tabular}{|c|c|c|}
\hline $\begin{array}{c}\text { Power } \\
\text { Class }\end{array}$ & $\begin{array}{c}\text { Power Density } \\
{\left[\mathbf{W} / \mathbf{m}^{2}\right]}\end{array}$ & $\begin{array}{c}\text { Generation } \\
\text { Potential }\end{array}$ \\
\hline 1 & $0<W P D \leq 200$ & Poor \\
\hline 2 & $200<W P D \leq 300$ & Marginal \\
\hline 3 & $300<W P D \leq 400$ & Moderate \\
\hline 4 & $400<W P D \leq 500$ & Good \\
\hline 5 & $500<W P D \leq 600$ & \multirow{2}{*}{ Excellent } \\
\cline { 1 - 2 } 6 & $600<W P D \leq 800$ & \multirow{2}{*}{} \\
\hline 7 & $800<W P D \leq 2000$ & \\
\hline
\end{tabular}

\subsection{The Effect of Windcatcher Height}

The other parameter which shall be considered is the height of the windcatcher to be installed. The wind speed curve according to the height is influenced significantly by the ground nature and by any obstacle (building, trees, rocks, etc.). To determine the wind speed profile as a function of the height, the below equation has been used:

$$
V_{i}=V_{o}\left(\frac{z_{i}}{z_{o}}\right)^{\alpha}
$$

The value of $\boldsymbol{\alpha}=\mathbf{0 . 1 6}$ was selected for this study, considering the site condition and obstacles according to Table 3:

Table 3. Value of $\boldsymbol{\alpha}$ based on the site condition

\begin{tabular}{|c|l|}
\hline$\alpha$ & \multicolumn{1}{|c|}{ Description } \\
\hline 0.09 & Calm sea \\
\hline 0.12 & $\begin{array}{l}\text { Open agricultural area with limited presence of } \\
\text { low obstacles }\end{array}$ \\
\hline 0.16 & $\begin{array}{l}\text { Open agricultural area with few middle-height } \\
(6-8 \mathrm{~m}) \text { substances }\end{array}$ \\
\hline 0.2 & $\begin{array}{l}\text { Agricultural area with the presence of a few } \\
\text { middle-height }(6-8 \mathrm{~m}) \text { obstacles }\end{array}$ \\
\hline 0.3 & Urban areas, woods \\
\hline
\end{tabular}

The shape and scale parameters at the desired height $\boldsymbol{h}\left(\boldsymbol{k}_{\boldsymbol{h}}\right.$ and $\left.\boldsymbol{c}_{\boldsymbol{h}}\right)$ can be calculated as:

$$
\left\{\begin{array}{c}
k_{h}=k_{0} \frac{1-0.088 \ln \left(h_{0} / 10\right)}{1-0.088 \ln (h / 10)} \\
c_{h}=c_{0}\left(\frac{h}{h_{0}}\right)^{\lambda}
\end{array}\right.
$$

where $\lambda=\frac{0.37-0.088 \ln \left(c_{0}\right)}{1-0.088 \ln (\boldsymbol{h} / 10)}$.

\section{ENVIRONMENTAL DATA AND CALCULATION RESULTS}

Geographically, Iran, due to their environmental conditions, has a high potential for exploiting new renewable energy resources such as solar and wind. One of the limitations of using wind energy is the rate of change in wind speed and its velocity vector. To install a wind power plant with a capacity of $100 \mathrm{MW}$, in the windy district of Manjil, Gilan, we look at the technical and economic feasibility. Specifically, a model of wind turbine that is less dependent on the wind direction compared to the traditional wind turbines.

\subsection{Location of the Project Site}

Located in Manjil, the area of the site is about 200 acres, enough for installing $100 \mathrm{MW}$ of wind turbines. The use of infrastructure facilities, including access roads and power transmission lines, is one of the advantages of this construction site. Manjil is a city in Northern Iran located in a valley between the Caspian Sea (with a humid climate) and the city of Ghazvin (with dry climate). Due to different climatic conditions and different air pressure at both sides of the valley, Manjil is a windy city, therefore sometimes known as the "City of Wind". Some geographical data for Manjil is provided in Table 4. Concepts related to the feasibility study of installing a $100 \mathrm{MW}$ INVELOX wind power system include: climatic conditions, WPD, grid connection, geology of the site, access roads for transportation, local human resources and expertise for installation and operation, environmental conditions, land area, and economic evaluation.

Table 4. Geographical data for Manjil, Gilan, Iran [26]

\begin{tabular}{|l|l|}
\hline Latitude & $36^{\circ} 43^{\prime} 42.4^{\prime \prime} \mathrm{N}$ \\
\hline Longitude & $49^{\circ} 24^{\prime} 36.0^{\prime \prime} \mathrm{E}$ \\
\hline Altitude (m) & 338.3 \\
\hline Mean Wind Speed (m/s) & 5.02 \\
\hline Max. Wind Speed (m/s) & 15.3 \\
\hline
\end{tabular}

\subsection{Regional Wind Studies}

In this regard, using the statistics from the Iran Meteorological Organization, the wind flow in the region was studied. In these studies, two important parameters related to wind are discussed. One is the value of wind speed at different times and directions and the other is the duration of the wind blowing at a certain speed. Table 5 is derived from studies on meteorological statistics and determines 
the wind speed in the Manjil region from 1993 to 2010. Fig. 5 shows the wind speed data for Manjil. Fig. 6 and Fig. 7 provide more extensive geographical information about Iran and Manjil.

Table 5. Average monthly wind speeds in Manjil \begin{tabular}{|l|l|l|l|l|l|l|l|l|l|l|l|l|l|}
\hline Year & Jan & Feb & Mar & Apr & May & Jun & Jul & Aug & Sep & Oct & Nov & Dec & Avg. \\
\hline
\end{tabular} \begin{tabular}{|l|l|l|l|l|l|l|l|l|l|l|l|l|l|}
\hline 1993 & 2.98 & 4.48 & 4.12 & 4.99 & 5.04 & 8.08 & 9.21 & 8.23 & 7.00 & 5.14 & 2.11 & 0.82 & 5.20 \\
\hline
\end{tabular} \begin{tabular}{|l|l|l|l|l|l|l|l|l|l|l|l|l|l|}
1994 & 1.80 & 4.53 & 4.06 & 5.45 & 6.17 & 10.96 & 11.63 & 10.60 & 7.25 & 4.58 & 2.47 & 2.62 & 6.02 \\
\hline
\end{tabular} \begin{tabular}{|l|l|l|l|l|l|l|l|l|l|l|l|l|l|l|l|l|l|l|l|l|l|l|l}
1995 & 2.42 & 2.83 & 4.01 & 4.89 & 6.02 & 7.61 & 11.11 & 10.08 & 7.77 & 5.61 & 1.75 & 1.23 & 5.45 \\
\hline
\end{tabular}

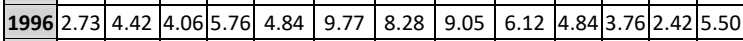
\begin{tabular}{|l|l|l|l|l|l|l|l|l|l|l|l|l|l|l|}
\hline 1997 & 3.45 & 4.53 & 5.97 & 5.81 & 6.84 & 9.98 & 11.57 & 9.93 & 9.05 & 4.37 & 2.78 & 2.57 & 6.38 \\
\hline
\end{tabular}

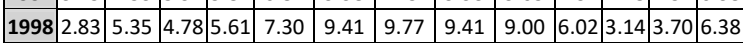
\begin{tabular}{|l|l|l|l|l|l|l|l|l|l|l|l|l|l|}
\hline 1999 & 3.81 & 4.37 & 6.58 & 7.30 & 9.98 & 11.52 & 11.57 & 9.88 & 9.72 & 5.97 & 4.12 & 2.37 & 7.25 \\
\hline
\end{tabular} \begin{tabular}{|l|l|l|l|l|l|l|l|l|l|l|l|l|l|}
\hline 2000 & 4.89 & 4.84 & 6.17 & 4.17 & 10.03 & 12.14 & 11.21 & 11.78 & 10.34 & 6.07 & 3.45 & 2.73 & 7.30 \\
\hline
\end{tabular} \begin{tabular}{|l|l|l|l|l|l|l|l|l|l|l|l|l|l|}
\hline 2001 & 3.24 & 4.17 & 6.17 & 6.43 & 8.69 & 11.68 & 11.37 & 10.65 & 8.85 & 6.12 & 3.34 & 3.45 & 7.00 \\
\hline
\end{tabular} \begin{tabular}{|l|l|l|l|l|l|l|l|l|l|l|l|l|l|l|}
\hline 2002 & 3.29 & 3.81 & 4.94 & 7.15 & 8.69 & 10.85 & 10.85 & 12.04 & 7.61 & 5.45 & 2.67 & 3.03 & 6.69 \\
\hline
\end{tabular} \begin{tabular}{|l|l|l|l|l|l|l|l|l|l|l|l|l|l|}
2003 & 2.67 & 3.03 & 6.02 & 6.84 & 6.69 & 11.01 & 11.27 & 8.54 & 8.38 & 4.37 & 3.14 & 2.06 & 6.17 \\
\hline
\end{tabular}

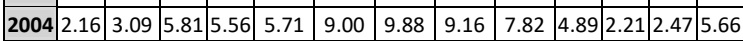
\begin{tabular}{|l|l|l|l|l|l|l|l|l|l|l|l|l|l|}
2005 & 1.65 & 2.52 & 4.32 & 5.66 & 5.20 & 9.98 & 10.13 & 9.52 & 8.44 & 5.14 & 2.47 & 2.26 & 5.61 \\
\hline 2006 & 2.37 & 2.16 & 4.53 & 4.63 & 6.53 & 9.21 & 9.62 & 6.43 & 7.36 & 4.22 & 2.83 & 2.01 & 5.14 \\
\hline
\end{tabular} \begin{tabular}{|l|l|l|l|l|l|l|l|l|l|l|l|l|l|}
\hline 2006 & 2.37 & 2.16 & 4.53 & 4.63 & 6.53 & 9.21 & 9.62 & 6.43 & 7.36 & 4.22 & 2.83 & 2.01 & 5.14 \\
\hline
\end{tabular} \begin{tabular}{|l|l|l|l|l|l|l|l|l|l|l|l|l|l|l|}
\hline 2007 & 1.70 & 3.24 & 4.89 & 4.84 & 5.45 & 7.97 & 9.16 & 7.77 & 7.05 & 4.37 & 3.34 & 1.95 & 5.14 \\
\hline
\end{tabular} \begin{tabular}{|l|l|l|l|l|l|l|l|l|l|l|l|l|l|l|l|}
2008 & 2.52 & 3.14 & 2.83 & 4.01 & 7.20 & 9.21 & 9.16 & 7.77 & 6.69 & 5.14 & 2.16 & 3.14 & 5.25 \\
\hline
\end{tabular} \begin{tabular}{|l|l|l|l|l|l|l|l|l|l|l|l|l|l|}
2009 & 2.42 & 2.52 & 4.63 & 5.50 & 6.38 & 6.74 & 8.95 & 9.16 & 6.12 & 4.22 & 2.88 & 1.95 & 5.14 \\
\hline
\end{tabular}

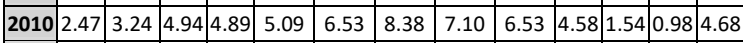
\begin{tabular}{|l|l|l|l|l|l|l|l|l|l|l|l|l|l|l|l|}
\hline Avg. 2.74 & 3.68 & 4.94 & 5.53 & 6.77 & 9.54 & 10.17 & 9.28 & 7.84 & 5.06 & 2.79 & 2.32 & 5.89 \\
\hline
\end{tabular}
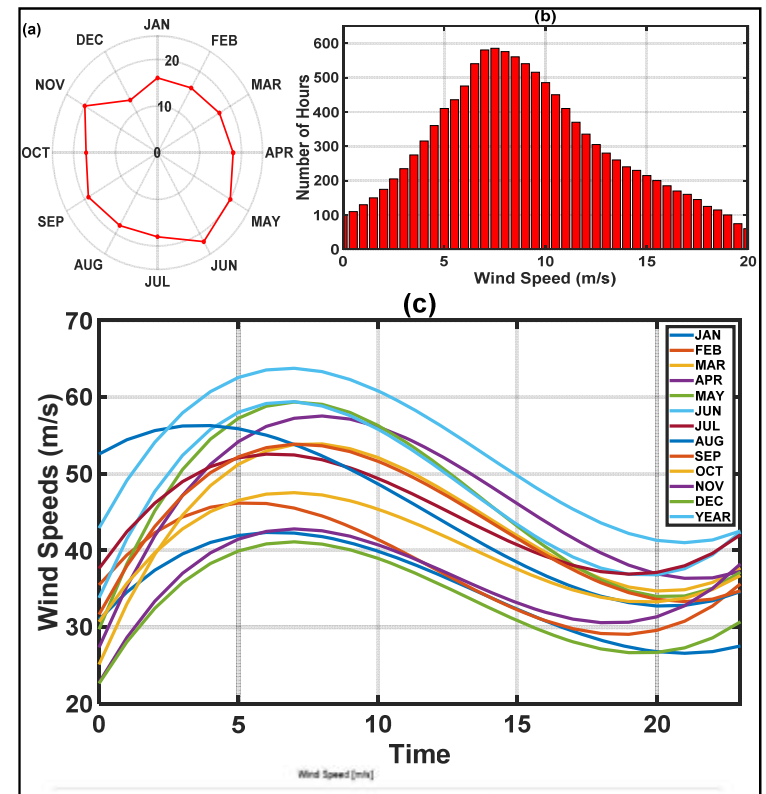

(d)

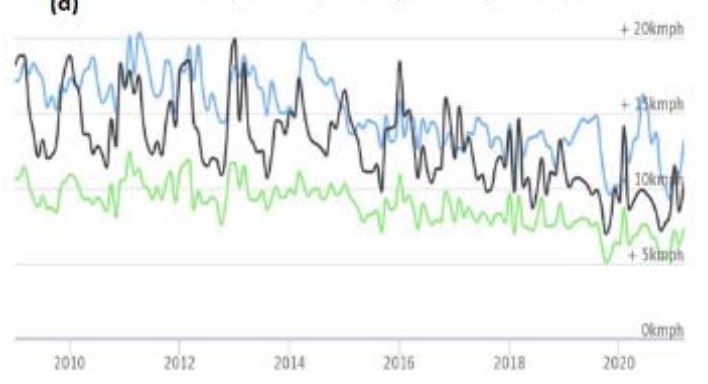

Fig. 5. Wind data for Manjil, Gilan, Iran: (a) monthly maximum wind speeds in $\mathrm{m} / \mathrm{s}$; (b) wind speed histogram; (c) average hourly wind speed in different months; and (b) maximum and mean wind and gust speed [27]

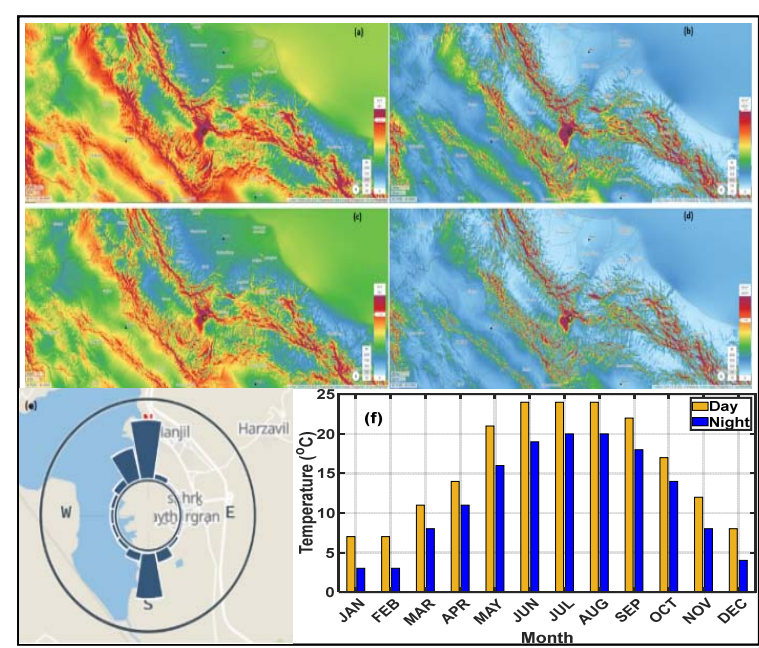

Fig. 6. (a) Mean wind speed at $100 \mathrm{~m}$; (b) mean WPD at $100 \mathrm{~m}$; (c) mean wind speed at $50 \mathrm{~m}$; (d) mean WPD at $50 \mathrm{~m} \mathrm{[28]} \mathrm{;} \mathrm{(e)} \mathrm{wind} \mathrm{direction} \mathrm{frequency} \mathrm{map;} \mathrm{and} \mathrm{(f)}$ monthly average temperature [29]

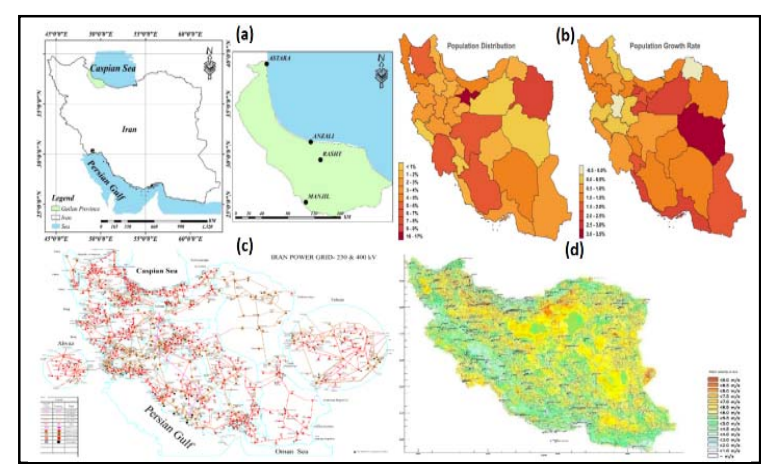

Fig. 7. Location and grid maps [10,30-34]: (a) Manjil's location in Gilan, Iran; (b) provincial population distribution and annual rate of population growth; (c) Iranian national grid; and (d) wind energy potential in Iran

\subsection{Calculating the Average Wind Power}

The variation of power of wind is not linear. Therefore, the mean power obtained over time in a variable wind with a mean velocity $\boldsymbol{V}_{\boldsymbol{m}}$ is not the same as the power obtained in a steady wind of the same speed. Therefore, in this investigation, a histogram of the frequency of different wind speed from data obtained from the Manjil weather station was prepared and the value used in the calculation of mean power. The standard deviation was calculated (0.59). The final mean power at a mean wind speed $v_{m}$, which is the steady power multiplied by the probability density distribution and summed over the range of wind speed:

$$
P_{m}\left(v_{m}\right)=\int_{0}^{\infty} w(v) \cdot p(v) d v
$$

Fig. 8 shows the changes in the $\boldsymbol{C}_{\boldsymbol{P}}$ value compared to the wind speed ratio. 


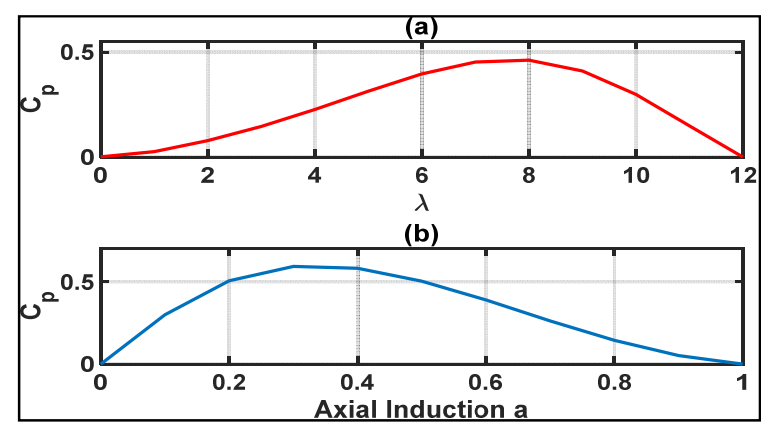

Fig. 8. (a) $C_{P}$ vs. TSR ( $\lambda$ ) and (b) $C_{P}$ vs. $a=v_{\text {out }} / v_{\text {in }}$

Fig. 9 shows the output curve of INVOLEX wind turbine in terms of wind speed.

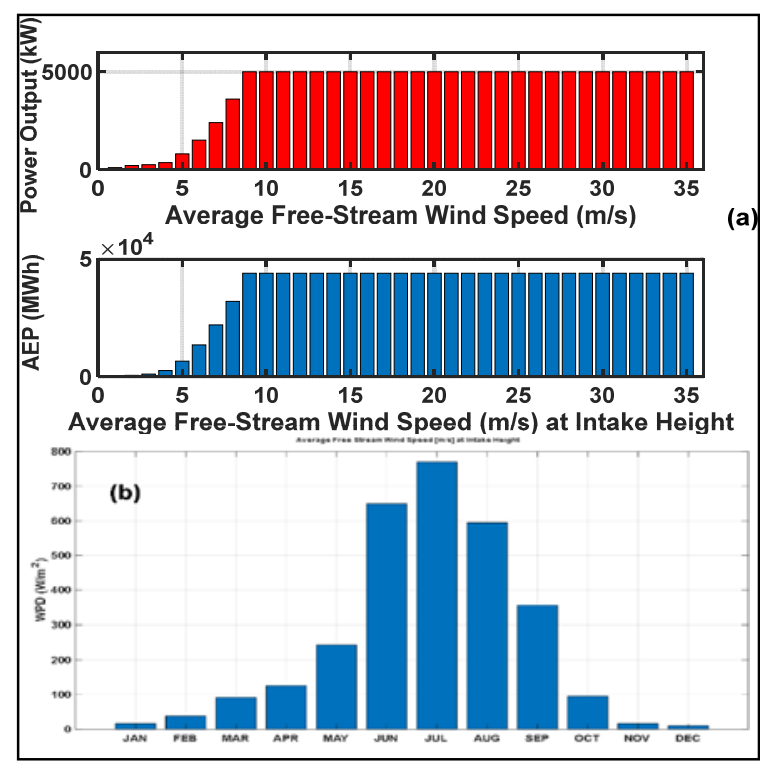

Fig. 9. (a) Power output and annual energy production (AEP) for different wind speeds and (b) monthly WPD calculated using MATLAB

The supply and demand of electricity consumption in the region were examined according to the predictions of the increasing regional electric load. In this regard, the necessary information was collected from the regional electric utility in the Gilan province. The information collected indicates the potential for increased power generation in the region. Another important parameter to study is the wind stability rate. As mentioned earlier, to determine the energy probability of a wind turbine, it is not sufficient to know the mean speed of the wind at a given site; it is also important that the data show for a defined period (e.g., one year) [35].

\section{INVELOX WIND SYSTEM}

Renewable energy sources have gained significance due to the continued depletion of fossil fuel resources. These sustainable sources of energy do not cause pollution and are renewable [36]. Traditional wind turbines are however, associated with some drawbacks, such as massive blades, which are harmful to the ecosystem and pose challenges in terms of repair and maintenance. The INVELOX system is designed to capture the wind from all directions and to increase the wind velocity using a convergent venturi section which creates higher velocity at the ground level. Traditionally, windmills utilize colossal turbine generator structures installed on the towers, however, INVELOX operates by funneling wind energy into generators on the ground. Rather than collecting small amounts of energy from blowing wind across the rotor blades, the INVELOX system harnesses wind using a conduit that leads it through a tapered passage, which naturally and passively increases the speed of its flow. This wind energy stream is then used to drive a generator at either sub-ground or ground levels [15].

The main innovative aspects of the INVELOX wind system are the exclusion of turbines mounted on towers, and the ability to capture wind irrespective of its direction. Massive turbine blades are hazardous to wildlife and people, inefficient, and costly [37]. Another element of the INVELOX system is its capacity to capture the flow of wind using an omnidirectional intake. This eliminates the need for active or passive yaw control. Thirdly, it can accelerate the flow inside the shrouded venturi part that subsequently expands and releases air into the environment using a diffuser [38]. Within the INVELOX, the actual wind turbine is positioned inside the system, allowing the external flow field to provide intake flow while matching the system's exhaust flow.

The INVELOX system, as shown in Fig. 10 (a), is composed of five main parts: (1) the intake, (2) pipe to carry and accelerate the wind, (3) venturi to boost wind speed, (4) a system for converting wind energy, as well as (5) a diffuser. Fig. 10 (b) shows an earlier installation of INVELOX in Iran.

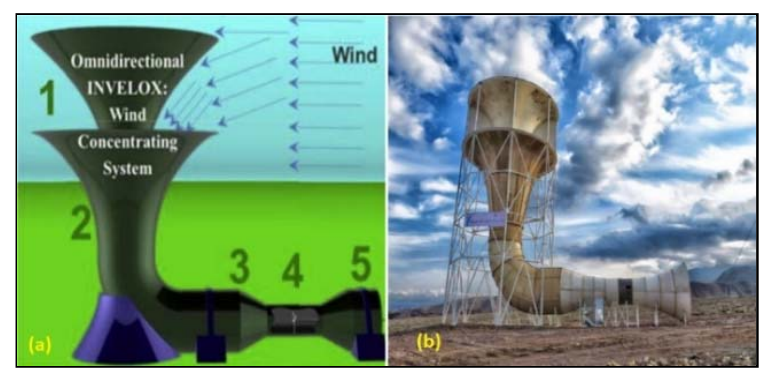

Fig. 10. (a) Structure of INVELOX system [39] and (b) previous installation of INVELOX in Iran [32] 
The INVELOX system captures airflow with speeds higher than $1 \mathrm{~m} / \mathrm{s}$. Then, the system passively changes the wind's existing potential and kinetic energy to higher kinetic energy, which is easier to convert to a turbine's mechanical rotation [40]. In all sections of the INVELOX tower, with a continuous cross-section, the speed does not change, which means the kinetic energy does not reduce as the wind passes across the turbine. Compared to previous systems of ducted turbines, the INVELOX system splits up the position of the turbine generator and the shroud. The opening is positioned at the uppermost part, whereas the turbine is positioned inside a ducted pipe at the ground level to direct wind to the turbine [41]. This exceptional feature enables engineers to alter the size of the system used to deliver the wind with any increase in speed needed without altering the size of the turbine. The intake size is dependent on the speed of local winds, along with other environmental characteristics. This implies that the size of the turbine can be chosen depending on the capacity of the INVELOX to intensify the rate of mass flow or wind speeds.

The installation of the generator is on the ground and within the optimal part of the flat sector of the INVELOX, which results in massive cost savings during installation, operation, and repairs in the life course of the system [39]. Since there are no moving components at the top of the tower, the INVELOX reduces the environmental impacts. Furthermore, optical flickering and radar interference caused by the traditional Horizontal Axis Wind Turbine (HAWT) blades can be avoided. The elimination of a large revolving turbine also enables INVELOX systems to be mounted close to other installations, which reduces the amount of land needed.

If a conventional turbine is utilized with a cut-in speed of approximately 4 meters per second, the INVELOX turbine system's cut-in speed will be 1 meter per second. Lower cut-in speed facilitates an increase in capacity factor. This allows INVELOX systems to be installed in areas with lower wind speeds [42]. Furthermore, the installation can be closer to the end-user [43]. Ultimately, it can decrease the general costs of wind power generation at a utility-scale through reduction of land, turbine, Operation and Maintenance (O\&M), and installation costs while decreasing environmental effects and enhancing the production of energy.

All ducted turbines created to date involve the coupling of the intake and location of the turbine.
Therefore, the process of scaling up the system to attain utility scale resulted in increased blade and duct size, as well as costs [44]. Some examples of failed ducted turbines did not provide further costsaving measures to pay off the increased costs of extra components, which were required to match the components with the trajectory of the wind [45]. Even though the INVELOX system is categorized under ducted turbines, some apparent dissimilarities make it more economically practical [46]. Decoupling of the turbine and the intake implies that the size of the intake can be altered while maintaining a small turbine, installed at the ground level, rated based on the required speed ratio and the environmental conditions $[47,48]$.

The decoupled venturi and intake at the point of installation of the turbine enables operation at higher wind speeds resulting in more power using smaller blades. Small rotors that rotate at higher velocities lead to cost efficiency in terms of installation, transportation, manufacturing, and materials [49]. The omnidirectional intake does not require large motors and bearings to shift the intake in the wind direction. It is possible to design the INVELOX system rated between $500 \mathrm{~W}$ and $25 \mathrm{MW}$ depending on the amount of air captured. The decoupled turbine and intake permit the linkage of multiple intakes to improve mass flow and, consequently, the power output. It is also possible to install the INVELOX in locations where traditional wind turbines may not be operational due to very low or very high wind speeds [50,51]. The generation of energy using the INVELOX system decreases the probability of harming wildlife [52].

The system operates at a high production efficiency ranging from $60-90 \%$. It is associated with low costs of production, faster returns on investment, easy repair and maintenance, and cleaner energy [53]. INVELOX can convert between $60-90 \%$ of its energy input into electrical power based on the wind speed and the site of installation [54].

In [32], authors provided a comparison between HAWT and INVELOX using Computational Fluid Dynamics (CFD). Results show $18-235 \%$ increase in power generation for different geographical locations while the costs for INVELOX were estimated to be much higher than a conventional HAWT. Concluding that this technology is more suitable for cities with a lower average wind speed. In another study [55], it was found that using the INVELOX wind turbine in the off-grid scenario is economically justifiable when the distance from the main grid is more than $1,288 \mathrm{~km}$. Numerical and 
experimental results in another study, [56], shows that despite not reaching a full wind omnidirectionality, $378-432 \%$ increase in energy production was utilized with an INVELOX system compared to a traditional one. It has been shown that the application of INVELOX turbines in microgrids can reduce the environmental pollution and total cost of microgrid considering the financial uncertainties [57].

The blades in an INVELOX system are considerably smaller than the typical ones, and are also placed at ground level, which adds to the flexibility of this already beneficial engine. Furthermore, it can be installed in places that have abrupt edges and can be independent of the central grid [58]. The omnidirectional wind intake feature eliminates the need for a yaw mechanism. It was also observed that by placing 2 and 3 turbines, compared to one turbine, there was increased power output. The addition of more turbines did not affect the performance of the first turbine, as the flow resistance through the system remained unchanged [59]. Several numerical and experimental studies have been conducted to find the optimum design parameters of the INVELOX system such as the diffuser angle [60], the upper intake's dimensions $[61,62]$, the guide vane's height [63], and the roof design [64]. Optimum design of the system using CFD analysis results in higher efficiency, lower losses, and maximized output power.

In the recent past, the INVELOX ducted turbines have managed to get significant investments and grants. Skepticism concerning the INVELOX system arises from the fact that previous ducted turbines did not provide any considerable progress due to financial viability and technical implementation, regardless of the positive performance. For example, a challenging technical aspect has been the impossible implementation of a structural design that self-aligns massive ducted turbines in the direction of the wind [65]. It is critical to ascertain where a generator is positioned within an INVELOX system as increased resistance can decrease power production, which negates the idea of improved efficiency. The same applies to conventional open-flow systems [66]. The speed of the wind is reduced when it nears the rotor because of the velocity resulting from the vortex structure shed within the generator. Mass conservation in ducted turbines like the INVELOX obligates that the velocity does not change either down or upstream.

The original wind turbine design used in this study was manufactured by Sheer Wind. The turbine used in this study, also known as the INVOLEX turbine (Fig. 11), is designed for such purposes.

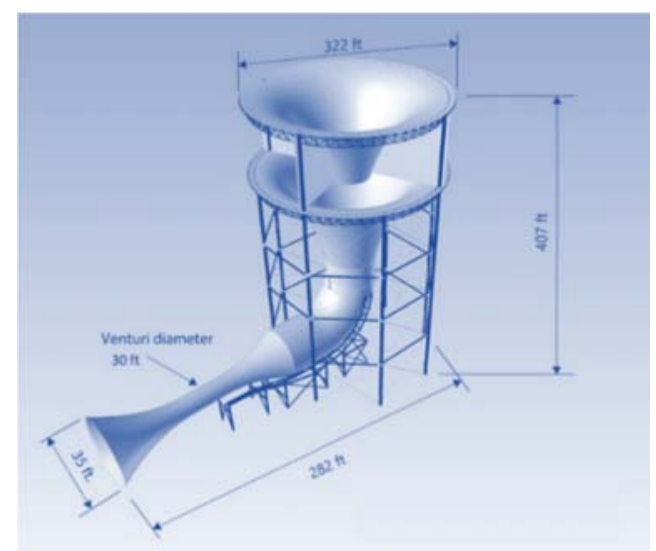

Fig. 11. INVELOX system's dimensions

\section{ECONOMIC ANALYSIS}

For the financial and economic evaluation of this project, COMFAR (Computer Model for Feasibility Analysis and Reporting) was applied. This software, designed by UNIDO (United Nations Industrial Development Organization), is applicable for the analysis of investment in new projects. Analysis was performed using a variety of assumptions concerning the inflation rate, currency revaluation, and price escalation.

In this study, the electric power supply and demand in the studied region were examined according to the predictions of the increasing regional electrical load. In this regard, the necessary information was collected from the regional electric utility in Gilan. The collected information on load prediction indicates the region's high need for increased electricity generation.

The costs incurred for the installation, operation, and maintenance of the wind power plant, the substation, and the connection to the provincial electric grid were calculated for a 20-year time window. To analyze the financial and economic feasibility of this project, the following items were considered and examined:

- Land cost: The land is given to the investor by the government; therefore, no extra cost is incurred.

- Land development and construction costs:

o Land development and site preparation works, drainage, etc.

o Excavation and embankment grading and earthworks

o Concrete works

- Preparation of access roads and providing lighting 
- Cost of constructing the required buildings

- Cost of machinery and equipment

- Cost of supplying (purchase and shipment) twenty 5-MW wind turbines

- Cost of equipment and ancillary facilities

- Cost of design, consulting engineers' and contractors' fees and other costs such as:

o Cost of feasibility studies

o Engineering cost

o Construction design cost

o Central office cost

o Cost of acquiring Clean Development Mechanism (CDM) permission

o Operating and maintenance costs: The operating costs include personnel wages, supplying consumables, and purchase of the required spare parts. The related repair costs in the power plant were also studied and examined.

In this study, the power plant's proceeds from electricity sales were calculated based on the approval of the Ministry of Energy, which determined the guaranteed purchase price of electricity. To estimate the Payback Period (PBP), the concept of Net Present Value (NPV) is used. The formulations used for the economic analysis based on the literature $([17,24,67])$ are presented in this section.

Generation Cost (GC) per kWh of energy can be determined by:

$$
G C=\frac{A C C}{A E P}+O \& M+F C
$$

where Annual Capital Cost (ACC) is in US\$/year, Annual Energy Production (AEP) is in kWh/year, and O\&M and Financing Cost (FC) are expressed in US\$/kWh. NPV is a strong indicator of the viability of the project and is determined by:

$$
N P V=\sum_{t=0}^{T} \frac{C_{t}}{(1+r)^{t}}
$$

where $\boldsymbol{C}_{\boldsymbol{t}}$ is the net cash inflow during the year $\boldsymbol{t}, \boldsymbol{r}$ is the interest rate, and $\boldsymbol{T}$ is the payback period [68]. The concept of NPV has widespread applications in economic feasibility analysis and optimal design of energy units [69]. A project with higher NPV is more profitable. A simple way to analyze the economic viability and merit of an investment by calculating its PBP, which is usually measured in years. To estimate the cost of energy, $\boldsymbol{C}_{\boldsymbol{i}}$ is considered as the initial investment of the wind turbine, and $\boldsymbol{C}_{\boldsymbol{o m}}$ as the operation and maintenance cost. $\boldsymbol{C}_{\boldsymbol{o m}}$ can be considered as a percentage of $\boldsymbol{C}_{\boldsymbol{i}}$ :

$$
C_{o m}=m C_{i}
$$

Typical economic parameters of a wind power system are shown in Table 6:

Table 6. Typical parameters of wind power plants

\begin{tabular}{|c|c|c|c|}
\hline $\begin{array}{c}\text { Economic } \\
\text { Life }\end{array}$ & Efficiency & $\begin{array}{c}\text { O\&M } \\
\text { Costs }\end{array}$ & $\begin{array}{c}\text { Full-Load } \\
\text { Hours }\end{array}$ \\
\hline 15 Years & $30-45 \%$ & $\begin{array}{c}1.5 \% \text { of } \\
\text { inv./year }\end{array}$ & $\begin{array}{c}2000 \\
\text { hours/year }\end{array}$ \\
\hline
\end{tabular}

Present Worth (PW) of operation and maintenance cost for the useful life of $\boldsymbol{n}$ years can be determined by:

$$
P W\left(C_{o m}\right)_{1-n}=m C_{i}\left[\frac{(1+I)^{n}-1}{I(1+I)^{n}}\right]
$$

where $\boldsymbol{I}$ is the rate of discount. The yearly operation cost of the wind turbine can be obtained as the Present Worth Cost (PWC):

$$
P W C=C_{i} / n\left\{1+m\left[\frac{(1+I)^{n}-1}{I(1+I)^{n}}\right]\right\}
$$

The yearly output energy produced by the wind turbine can be estimated as:

$$
E_{o u t}=8760 * P_{r} C_{f}
$$

where $\boldsymbol{P}_{\boldsymbol{r}}$ and $\boldsymbol{C}_{\boldsymbol{f}}$ are the rated power and capacity factor of the wind turbine, respectively. Therefore, the cost of electrical power generated by the wind turbine in terms of money/kWh is calculated as:

$$
C=\frac{P W C}{E_{\text {out }}}=\frac{C_{i}}{8760 n P_{r} C_{f}}\left\{1+m\left[\frac{(1+I)^{n}-1}{I(1+I)^{n}}\right]\right\}
$$

PBP, which is the period that the investor would recover the initial investment, can be calculated as:

$$
P B P=-\frac{\ln \left(1-\frac{I C_{i}}{E U A B-m C_{i}}\right)}{\ln (1+I)}
$$

where EUAB (Equivalent Uniform Annual Benefit) is calculated by:

$$
E \boldsymbol{E} B=\frac{C_{i}\left\{1+m\left[\frac{(1+I)^{n}-1}{I(1+I)^{n}}\right]\right\}}{\left[\frac{(1+I)^{n}-1}{I(1+I)^{n}}\right]}
$$

The power purchase tariff regulated by Renewable Energy and Energy Efficiency Organization for wind farms with a capacity above $50 \mathrm{MW}$ is 3,400 Iranian Rials per kWh [10]. Based on the current inflation rates, the PBP of this project was estimated to be less than 10 years.

According to the Kyoto Protocol, countries with high rates of pollution can buy the credit they need from the countries that do not use their credit to increase the pollution rate more than what was set in the protocol. Countries that do not use all their credit can sell it to countries that produce more pollutant gases than they are permitted to. Through this study, it was observed that producing $100 \mathrm{MW}$ 
of electricity through a wind farm reduces about 48,100 tons of $\mathrm{CO}_{2}$ per year. In addition, given that the price per ton of carbide oxide produced under the Kyoto Treaty is $€ 78$, a power plant would save about $€ 3,367$ annually (which was included in the economic feasibility study).

Wind turbine's efficiency can decrease over time due to dust and insect carcasses on the blades and aging up to $1.2 \%$ per year [70]. Wind turbines installed in more stable and constant weather conditions depict a significantly higher efficiency $[7,8]$. According to the data presented in Table 5, the wind stability rate in the Manjil is over $82 \%$, which makes it a great choice for the installation of the wind turbine.

\section{CONCLUSION}

This paper aims to provide a comprehensive feasibility study for the installation of an INVELOX wind power plant in the city of Manjil, Gilan in Northern Iran. We first provided the mathematical formulation for calculating the potential wind power and energy for any geographical location. The geographical and environmental data for Manjil was collected and analyzed to calculate the expected wind power density using PDM and MATLAB. A comprehensive literature review of the INVELOX wind system, its operation mechanism, its benefits and limitations, and the corresponding practical considerations were presented and discussed. The optimal design of the system was performed using CFD. After collecting the information on the initial and current costs and the power plant's revenue after the operation, the payback period was calculated using the software package COMFAR. The results of the study showed that the investment in this project is economically feasible.

\section{ACKNOWLEDGEMENT}

Pooya Taheri would like to thank Ms. Cindy Cen and Ms. Alison Roberts for their valuable editorial contributions.

\section{REFERENCES}

[1] L. Ding, Study of INVELOX wind turbine considering atmospheric boundary layer: Based on numerical simulation. Journal of Physics: Conference Series, 1600, 2020: 1-6. https://doi.org/10.1088/1742$\underline{6596 / 1600 / 1 / 012063}$
[2] M. Anbarsooz, M. Amiri, I. Rashidi, A novel curtain design to enhance the aerodynamic performance of INVELOX: A Steady-RANS numerical simulation. Energy, 168, 2019: 207221.

https://doi.org/10.1016/j.energy.2018.11.122

[3] O. Saadatian, L. C. Haw, K. Sopian, M. Y. Sulaiman, Review of windcatcher technologies. Renewable and Sustainable Energy Reviews, 16(3), 2012: 1477-1495.

https://doi.org/10.1016/j.rser.2011.11.037

[4] F. Jomehzadeh, P. Nejati, J. K. Calautit, M. B. Mohd Yusof, S. A. Zaki, B. R., Hughes, M. N. A. W. M. Yazid, A review on windcatcher for passive cooling and natural ventilation in buildings, Part 1: Indoor air quality and thermal comfort assessment. Renewable and Sustainable Energy Reviews, 70, 2017: 736756. https://doi.org/10.1016/j.rser.2016.11.254

[5] A. El-Shorbagy, Design with nature: windcatcher as a paradigm of natural ventilation device in buildings. International Journal of Civil \& Environmental Engineering (IJCEE-IJENS), 10(3), 2010: 26-31.

[6] Ministry of Energy Renewable Energy and Energy Efficiency Organization, Online: http://www.satba.gov.ir/en/aboutsatba/ener gystrategicplanning, (Accessed: 29.04.2021).

[7] T. Burton, N. Jenkins, D. Sharpe, E. Bossanyi, Wind energy handbook, Second Ed., John Wiley \& Sons, May 2011. https://doi.org/10.1002/9781119992714

[8] S. Moshiri, S. Lechtenböhmer, Sustainable energy strategy for Iran, Wuppertal Spezial, 51, Wuppertal Institut für Klima, 2015.

[9] Wind Report 2021, Online: https://gwec.net/global-wind-report-2021/, (Accessed: 29.04.2021).

[10] M. Aien, O. Mahdavi, On the way of policy making to reduce the reliance of fossil fuels: Case study of Iran. Sustainability, 12(24), 2020. https://doi.org/10.3390/su122410606

[11] The Wind Power, Online: https://www.thewindpower.net/countrydatasheet-38-iran.php, (Accessed: 29.04.2021).

[12] Naft Online News Agency, Online: https://www.naftonline.ir/, (Accessed: 29.04.2021).

[13] A. A. Sayed, M. Z. Ibn Sadiq, Q. N. Rudaba, S. Khondokar, A. H. S. Shatil, Generating electricity on roadside using INVELOX, $2^{\text {nd }}$ IEEE International Conference on Power Electronics, 
Intelligent Control and Energy Systems (ICPEICES), Oct. 2018, New Delhi, India, pp.1132-1135.

https://doi.org/10.1109/icpeices.2018.889731 $\underline{4}$

[14] A. Mostafaeipour, H. Abarghooei, Harnessing wind energy at Manjil area located in north of Iran. Renewable and Sustainable Energy Reviews, 12(6), 2008: 1758-1766. https://doi.org/10.1016/i.rser.2007.01.029

[15] D. Allaei, D. Tarnowski, Y. Andreopoulos, INVELOX with multiple wind turbine generator systems, Energy, 93(1), 2015: 1030-1040. https://doi.org/10.1016/j.energy.2015.09.076

[16] A. Betz, Introduction to the Theory of Flow Machines. Oxford: Pergamon Press, 1966. https://doi.org/10.1016/c2013-0-05426-6

[17] A. Mostafaeipour, A. Sedaghat, A. A. DehghanNiri, V. Kalantar, Wind energy feasibility study for Shahrbabak in Iran. Renewable and Sustainable Energy Reviews, 15(6), 2011: 25452556. https://doi.org/10.1016/j.rser.2011.02.030

[18] A. K. Azad, M. G. Rasul, T. Yusuf, Statistical diagnosis of the best Weibull methods for wind power distribution function for agricultural applications. Energies, 7(5), 2014: 3056-3085. https://doi.org/10.3390/en7053056

[19] P. K. Chaurasiya, S. Ahmed, V. Warudkar, Study of different parameters estimation methods of Weibull distribution to determine wind power density using ground based Doppler SODAR instrument. Alexandria Engineering Journal, 57(4), 2018: 2299-2311.

https://doi.org/10.1016/j.aej.2017.08.008

[20] B. K. Saxena, K. V. S. Rao, Estimation of wind power density at a wind farm site located in western Rajasthan region of India. Procedia Technology, 24, 2016: 492-498. https://doi.org/10.1016/j.protcy.2016.05.084

[21] K. Mohammadi, A. Mostafaeipour, A. Sedaghat, S. Shamshirband, D. Petković, Application and economic viability of wind turbine installation in Lutak, Iran. Environmental Earth Science, 75(3), 2016. https://doi.org/10.1007/s12665-015-5054-7

[22] D. B. de Alencar, C. de Mattos Affonso, R. C. L. de Oliveira, J. L. M. Rodriguez, J. C. Leite, J. C. R. Filho, Different methods for forecasting wind power generation: Case study. Energies, 10(12), 2017.

https://doi.org/10.3390/en10121976

[23] K. Mohammadi, A. Mostafaeipour, Using different methods for comprehensive study of wind turbine utilization in Zarrineh, Iran. Energy Conversion and Management, 65, 2013: 463-470.

https://doi.org/10.1016/j.enconman.2012.09. $\underline{004}$

[24] K. Mohammadi, A. Mostafaeipour, Y. Dinpashoh, N. Pouya, Electricity generation and energy cost estimation of large-scale wind turbines in Jarandagh, Iran. Journal of Energy, 2014.

https://doi.org/10.1155/2014/613681

[25] X. Yu, H. Qu, Wind power in China Opportunity goes with challenge. Renewable and Sustainable Energy Reviews, 14(8), 2010: 2232-2237.

https://doi.org/10.1016/i.rser.2010.03.038

[26] S. Samadianfard, S. Hashemi, K. Kargar, M. Izadyar, A. Mostafaeipour, A. Mosavi, N. Nabipour, S. Shamshirban, Wind speed prediction using a hybrid model of the multilayer perceptron and whale optimization algorithm. Energy Reports, 6, 2020: 1147-1159. https://doi.org/10.1016/j.egyr.2020.05.001

[27] World Weather Online, Online: https://www.worldweatheronline.com/manjil -weather-averages/gilan/ir.aspx, (Accessed: 29.04.2021).

[28] Global Wind Info, Online: https://globalwindatlas.info/, (Accessed: 29.04.2021)

[29] Windy App, https://windy.app/forecast2/spot/459382/Ma njil/statistics, (Accessed: 29.04.2021).

[30] A. Ashrafzadeh, O. Kişi, P. Aghelpour, S. M. Biazar, M. A. Masouleh, Comparative study of time series models, support vector machines, and GMDH in forecasting long-term evapotranspiration rates in Northern Iran. Journal of Irrigation and Drainage Engineering, 146(6), 2020.

https://doi.org/10.1061/(asce)ir.19434774.0001471

[31] F. Roudi, P. Azadi, M. Mesgaran, Iran's population dynamics and demographic window of opportunity, Stanford Iran 2040 Project. Stanford University, April 2017.

[32] Iranian power system, CIGRÉ report, 2018. https://www.cigre.org/userfiles/files/Commu nity/NC/2018 National-powersystem Iran.pdf, (Accesses: 29.04.2021)

[33] M. Meratizaman, M. Nateqi, Feasibility study of new generation of wind turbine (INVELOX), is it competitive with the Conventional 
Horizontal Axis Wind Turbine?. Energy, 217, 2021.

https://doi.org/10.1016/i.energy.2020.11935 $\underline{0}$

[34] N. Nikandish, H. A. Ghamsari, An investigation of Manjil wind changes and its effect on sustainable development of the region. Geography and Development, 18(59), 2020.

[35] A. Genc, M. Erisoglu, A. Pekgor, G. Oturanc, A. Hepbasil, K. Ulgen, Estimation of wind power potential using Weibull distribution, Energy Sources, 27(9), 2005: 809-822.

https://doi.org/10.1080/00908310490450647

[36] I. Ackah, E. Graham, Meeting the targets of the Paris Agreement: an analysis of Renewable Energy (RE) governance systems in West Africa (WA), Clean Technologies and Environmental Policy, 23(2), 2021: 501-507. https://doi.org/10.1007/s10098-020-01960-6

[37] M. Shaterabadi, M. Ahmadi Jirdehi, Multiobjective stochastic programming energy management for integrated INVELOX turbines in microgrids: A new type of turbines. Renewable Energy, 145, 2020: 2754-2769. https://doi.org/10.1016/i.renene.2019.08.002

[38] M. Jithim, R. N. Hegde, Innovative wind energy generation by INVELOX, $4^{\text {th }}$ IRF International Conference, Apr. 2015, Cochin, India.

[39] D. Allaei, Y. Andreopoulos, INVELOX: Description of a new concept in wind power and its performance evaluation. Energy, 69, 2014: 336-344.

https://doi.org/10.1016/j.energy.2014.03.021

[40] S. Hanna, Introducing INVELOX technology to generate energy using wind and wind turbines by retrofitting traditional wind turbines, M.Sc. Thesis. California State University, Sacramento, US, 2019.

[41] P. Raeisi Mahdi Abadi, S. Vahdati Daneshmand, R. Sharifi, Development and economical evaluation for wind power plant in Chabahar in Sistan and Baluchestan province-Iran. Journal of Renewable Energy and Environment, 3(1), 2015: 17-24.

[42] M. Ahmadi Jirdehi, M. Shaterabadi, Incentive programs caused by the CCUS technology profit's effect: Optimal configuration and energy planning of hybrid microgrid involving INVELOX turbine. Energy Technology, 8(10), 2020: 1-13.

https://doi.org/10.1002/ente.202000398

[43] M. Casini, Small vertical axis wind turbines for energy efficiency of buildings. Journal of Clean Energy Technologies, 4(1), 2016: 56-65. https://doi.org/10.7763/jocet.2016.v4.254

[44] F. Sotoudeh, R. Kamali, S. M. Mousavi, Field tests and numerical modeling of INVELOX wind turbine application in low wind speed region, Energy, 181, 2019: 745-759.

https://doi.org/10.1016/j.energy.2019.05.186

[45] M. Shaterabadi, M. Ahmadi Jirdehi, N. Amiri, S. Omidi, Enhancement the economical and environmental aspects of plus-zero energy buildings integrated with INVELOX turbines. Renewable Energy, 153, 2020: 1355-1367. https://doi.org/10.1016/j.renene.2020.02.089

[46] M. Anbarsooz, M. S. Hesam, B. MoetakefImani, Numerical study on the geometrical parameters affecting the aerodynamic performance of INVELOX. IET Renewable Power Generation, 11(6), 2017: 791-798. https://doi.org/10.1049/iet-rpg.2016.0668

[47] G. A. Gohar, T. Manzoor, A. Ahmad, Z. Hameed, F. Saleem, I. Ahmad, A. Sattar, A. Arshad, Design and comparative analysis of an INVELOX wind power generation system for multiple wind turbines through computational fluid dynamics. Advances in Mechanical Engineering, 11(4), 2019: 1-10. https://doi.org/10.1177/1687814019831475

[48] S. R. Hosseini, D. Domiri Ganji, A novel design of nozzle-diffuser to enhance performance of INVELOX wind turbine. Energy, 198, 2020: 116.

https://doi.org/10.1016/i.energy.2020.11708 $\underline{2}$

[49] M. N. Patil, S. M. Ghadage, O. R. Gaikwad, D. V. Suryawanshi, A. D. Haral, Design and fabrication of INVELOX. International Research Journal of Engineering and Technology (IRJET), 6(6), 2019: 765-768.

[50] A. Sedaghat, R. Al Waked, M. El Haj Assad, M., K. Khanafer, M. N. Bani Salim, Analysis of accelerating devices for enclosure wind turbines. International Journal of Astronautics and Aeronautical Engineering, 2(2), 2017: 1-14. https://doi.org/10.35840/2631-5009/7509

[51] F. Nardecchia, D. Groppi, D. A., Garcia, L. de Santoli, Increasing energy production of a ducted wind turbine system. Wind Engineering, 4(46), 2020: 560-576. https://doi.org/10.1177/0309524×19862760

[52] S. M. Baque Billah, S. Qasim, Development of MATLAB Simulink model of INVELOX to analyze the impact of inlet height on speed ratio, IEEE International Conference on Energy and Power Engineering (ICEPE), Mar. 2019, Dhaka, Bangladesh. 
https://doi.org/10.1109/cepe.2019.8726795

[53] A. Golozar, F. A. Shirazi, S. Siahpour, F. N. Khakiani, K. Gaemi Osguei, A novel aerodynamic controllable roof for improving performance of INVELOX wind delivery system. Wind Engineering, 45(3), 2020: 477-490. https://doi.org/10.1177/0309524×20910986

[54] A. A. Sayed, M. Z. Ibn Sadiq, Generating electricity using INVELOX and a better one compared to traditional wind turbine, $2^{\text {nd }}$ International Conference on Robotics, Electrical and Signal Processing Techniques (ICREST), Oct. 2018, New Delhi, India. https://doi.org/10.1109/icrest.2019.8644316

[55] M. Jahangiri, A. Alidadi Shamsabadi, O. Nematollahi, A. Mostafaeipour, Enviroeconomic investigation of a new generation of wind turbines. International Journal of Strategic Energy \& Environmental Planning, 2(3), 2020: 43-59.

[56] F. Nardecchia, D. Groppi, D. A. Garcia, F. Bisegna, L. de Santoli, A new concept for a mini ducted wind turbine system. Renewable Energy, 175, 2021: 610-624. https://doi.org/10.1016/i.renene.2021.04.097

[57] M. Ahmadi Jirdehi, M. Shaterabadi, A lowcarbon strategy using INVELOX turbines in the presence of real-time energy price uncertainty. Greenhouse Gases: Science and Technology, 11(3), 2021: 461-482. https://doi.org/10.1002/ghg.2060

[58] K. Panagiotis, The historic development of the modern wind turbine, M.Sc. Thesis. International Hellenic University, Nov. 2018.

[59] V. S. Ragunath, J. K. Pandey, A. K. Mondal, A. Karn, Electricity generation from wind turbines at low wind velocities: A review. SSRN Electronic Journal, 2019. https://doi.org/10.2139/ssrn.3372736

[60] S. Suthagar, T. Kumaran, G. Gowtham, T. Maridurai, T. Sathish, S. Deivanayagi, Computational analysis of INVELOX wind turbine to analyze the venturi velocity by change the parameter of diffuser. Materials Today: Proceedings, 46, 2021: 4245-4249. https://doi.org/10.1016/j.matpr.2021.03.049

[61] A. Farokhzade, M. J. Maghrebi, Inlet parameters effects of INVELOX on the aerodynamic performance using numerical simulation. Journal of Applied Fluid Mechanics, 14(5), 2021: 1511-1520.

http://doi:10.47176/jafm.14.05.32554

[62] S. Shayestehnezhad, S. Kargar, A. Lohrasbi Nichkoohi, A numerical study of INVELOX wind turbine considering the inlet shape design, $7^{\text {th }}$ Iran Wind Energy Conference (IWEC2021), May 2021, Shahrood, Iran.

https://doi.org/10.1109/iwec52400.2021.946 $\underline{6962}$

[63] T. R. Reddy, C. I. Priyadarsini, M. V. S. M. Krishna, Guide vane height effect on performance of sheer wind turbine. Journal of Xi'an University of Architecture \& Technology, XIII(5), 2021: 482-489.

[64] S. Siahpour, F. N. Khakiani, V. Fazlollahi, A. Golozar, F. A. Shirazi, Morphing omnidirectional panel mechanism: A novel active roof design for improving the performance of the wind delivery system. Energy, 217, 2021. https://doi.org/10.1016/j.energy.2020.11940 $\underline{0}$

[65] M. Aghbashlo, M. Tabatabaei, S. S. Hosseini, B. B. Dashti, M. M. Soufiyan, Performance assessment of a wind power plant using standard exergy and extended exergy accounting (EEA) approaches. Journal of Cleaner Production, 171, 2018: 127-136. https://doi.org/10.1016/j.jclepro.2017.09.263

[66] J. Taghinezhad, R. Alimardani, H. Mosazadeh, M. Masdari, Ducted wind turbines: A review. International Journal on Future Revolution in Computer Science \& Communication Engineering, 5(4), 2019: 19-25.

[67] S. Mathew, Wind energy: Fundamentals, resource analysis and economics. SpringerVerlag Berlin Heidelberg, 2006. https://doi.org/10.5860/choice.44-0337

[68] F. C. Jelen, J. H. Black, Cost and optimization engineering. McGraw Hill Higher Education, 1982.

[69] M. J. Taheri, P. Taheri, Feasibility study of cogeneration for a gas power plant, IEEE Electrical Power and Energy Conference (EPEC 2017), Oct. 2017, Saskatoon, Canada. https://doi.org/10.1109/epec.2017.8286154

[70] W. K. Rao, Wind energy for power generation. Springer Nature, 2019. https://doi.org/10.1007/978-3-319-75134-4 